\title{
Application of 3,4-dihydroxycinnamic acid as a suitable mediator and multiwall carbon nanotubes as a sensor for the electrocatalytic determination of L-cysteine
}

\author{
Mohsen Keyvanfard a,*, Rasoul Salmani-mobarakeh b, Hassan Karimi-Maleh c,\#, Khadijeh Alizad a \\ a Department of Chemsitry, Majlesi Branch, Islamic Azad University, Isfahan, Iran \\ b Department of Chemistry, Shahreza Branch, Islamic Azad University, Isfahan, Iran \\ c Department of Chemistry, Graduate University of Advanced Technology, Kerman, Iran
}

\section{A R T I C L E I N F O}

\section{Article history:}

Received 9 November 2013

Accepted 28 February 2014

Published 20 July 2014

Keywords:

L-Cysteine

Multiwall carbon nanotube

Voltammetry

3,4-Dihydroxycinnamic acid

\author{
A B S T R A C T
}

A highly sensitive electrochemical sensor was prepared for the determination of L-cysteine using a modified multiwall carbon nanotubes paste electrode in the presence of 3,4-dihydroxycinnamic acid (3,4-DHCA) as a mediator, based on an electrocatalytic process. The results indicate that the electrode is electrocatalytically efficient for the oxidation of L-cysteine in the presence of 3,4-DHCA. The interaction between the mediator and L-cysteine can be used for its sensitive and selective determination. Using chronoamperometry, the catalytic reaction rate constant was calculated to be 2.37 $\times 10^{2} \mathrm{~mol}^{-1} \mathrm{~L} \mathrm{~s}^{-1}$. The catalytic peak current was linearly dependent on the L-cysteine concentration in the range of $0.4-115 \mu \mathrm{mol} / \mathrm{L}$. The detection limit obtained by linear sweep voltammetry was 0.25 $\mu \mathrm{mol} / \mathrm{L}$. Finally, the modified electrode was examined as a selective, simple, and precise new electrochemical sensor for the determination of L-cysteine in real samples.

(C) 2014, Dalian Institute of Chemical Physics, Chinese Academy of Sciences. Published by Elsevier B.V. All rights reserved.

\section{Introduction}

Amino acids are a class of biologically significant organic compounds because of their incorporation in the molecular structure of proteins. Amino acids can be metabolized to produce energy. This is especially important during fasting when the breakdown of muscle protein is a major energy source. Cysteine is an important sulfur containing amino acid. It is a semi-essential amino acid, which means that it can be biosynthesized in humans [1]. L-Cysteine is a highly significant bioactive compound and is known to be an active site in the catalytic function of certain enzymes known as cysteine proteases, and in many other peptides and proteins [2]. Different methods have been reported for the determination of L-cysteine in biological samples. These include chromatography [3-5], electro- phoresis [6], spectrophotometry [7-10], and chemiluminescence [11]. Electroanalytical methods have attracted much attention in recent years for the determination of L-cysteine and other thiol compounds because of their high sensitivity, accuracy, low cost, and simplicity [12-15]. It is well known that the direct electrochemical oxidation of L-cysteine at the surface of a bare carbon electrode is irreversible; therefore, a high overpotential is required for their oxidation [15]. Thus, modified electrodes are necessary for the determination of this compound.

Carbon nanotubes (CNTs) are significant nanostructural materials that are used as building blocks in nanotechnology. CNTs have generated much interest for future applications because of their field emission and electron transport properties, their high mechanical strength and high conductivity [16].

\footnotetext{
* Corresponding author. Tel: +98-913-1009952; Fax: +98-311-6732054; E-mail: keyvan45638@yahoo.com \# Corresponding author. Tel: +98-911-2540112; Fax: +98-3426226617; E-mail: h.karimi.maleh@gmail.com DOI: 10.1016/S1872-2067(14)60065-6 | http://www.sciencedirect.com/science/journal/18722067 | Chin. J. Catal., Vol. 35, No. 7, July 2014
} 
The modification of electrode substrates with CNTs for use in analytical sensing has been reported to result in low detection limits, high sensitivities, the reduction of overpotentials, and resistance to surface fouling [17-22].

In a continuation of our recent studies concerning the preparation of chemically modified electrodes [23-30], we describe the application of a multiwall CNT paste electrode (MWCNTPE) as a voltammetric sensor for the determination of L-cysteine in the presence of 3,4-dihydroxycinnamic acid (3,4-DHCA) as a suitable mediator. Additionally, we used the modified electrode as a new and sensitive sensor for the determination of L-cysteine in real samples such as urine, water, and serum.

\section{Experimental}

\subsection{Apparatus and reagents}

All the voltammetric measurements were performed using an Autolab PGSTAT 302N potentiostat/galvanostat (Utrecht, the Netherlands) connected to a three-electrode cell, and a Metrohm (Herisau, Switzerland) Model 663 VA stand linked to a computer (Pentium IV, 1,200 MHz). Autolab software was also used. A platinum wire was used as the auxiliary electrode. The MWCNTPE and $\mathrm{Ag} / \mathrm{AgCl} / \mathrm{KCl}_{\text {sat }}$ were used as the working and reference electrodes, respectively. The electrode prepared with CNTs was characterized by scanning electron microscopy (SEM) (Seron Tech. AIS 2100). A digital pH/mV-meter (Metrohm model 710) was used for $\mathrm{pH}$ measurements. Spectrally pure graphite powder (particle size $<50 \mu \mathrm{m}$ ) from Merck and MWCNTs ( $>90 \%$ MWCNTs basis, $d \times l=(90-70 \mathrm{~nm}) \times(5-9$ $\mu \mathrm{m})$ from Fluka were used as the substrate for the preparation of the carbon paste electrode.

Phosphate buffer $\left(\mathrm{NaH}_{2} \mathrm{PO}_{4}-\mathrm{Na}_{2} \mathrm{HPO}_{4}-\mathrm{NaOH}, 0.1 \mathrm{~mol} / \mathrm{L}\right)$ solutions (PBS) with different $\mathrm{pH}$ values were used.

All chemicals used were of analytical reagent grade and purchased from Merck (Darmstadt, Germany) unless otherwise stated. Doubly distilled water was used throughout. L-cysteine and 3,4-DHCA were purchased from Merck.

\subsection{Preparation of the electrode}

Graphite powder $(0.900 \mathrm{~g}$ ) was dissolved in diethyl ether and hand mixed with $0.100 \mathrm{~g}$ CNTs in a mortar and pestle. The solvent was evaporated by stirring. A syringe was used to add paraffin to the mixture, which was mixed well for 50 min until a uniformly wetted paste was obtained. The paste was then packed into a glass tube. Electrical contact was made by pushing a copper wire down the glass tube into the back of the mixture. When necessary, a new surface was obtained by pushing excess paste out of the tube and polishing it with weighing paper.

\subsection{Preparation of real samples}

Urine samples were stored in a refrigerator immediately after collection. Each sample $(10 \mathrm{~mL})$ was centrifuged for $10 \mathrm{~min}$ at $2000 \mathrm{r} / \mathrm{min}$. The supernatant was filtered using a filter $(0.45$ $\mu \mathrm{m})$ and then diluted 100 times with universal buffer solution $(\mathrm{pH}=7.0)$. The solution was transferred to a voltammetric cell for analysis without any further pretreatment. The standard addition method was used for the determination of L-cysteine in the real samples.

\subsection{Optimization of the 3,4-DHCA concentration}

The influence of 3,4-DHCA concentration on the electrocatalytic oxidation peak current was studied at $\mathrm{pH}=7.0$, and in the range of 300 to $800 \mu \mathrm{mol} / \mathrm{L}$ 3,4-DHCA. As shown in Fig. 1, by increasing the concentration of 3,4-DHCA up to $500 \mu \mathrm{mol} / \mathrm{L}$ the net electrocatalytic peak current increased, whereas higher concentrations of 3,4-DHCA caused a decrease of the magnitude of the peak current, which may be due to the formation of 3,4-DHCA aggregates. Therefore, a 3,4-DHCA concentration of $500 \mu \mathrm{mol} / \mathrm{L}$ was selected for further study.

\section{Results and discussion}

\subsection{Characteristics of the MWCNTPE}

Figure 2 shows SEM images of CPE and MWCNTPE. On the surface of the CPE, a layer of irregular flakes of graphite powder was present and they were isolated from each other. After MWCNTs were added to the carbon paste, the MWCNTs were distributed on the surface of the electrode in a special three-dimensional structure, indicating that the MWCNTs successfully modified the electrode.

The active surface areas of the modified electrodes were estimated from the slope of a $I_{\mathrm{p}}$ vs $v^{1 / 2}$ plot for a known concentration of $\mathrm{K}_{2} \mathrm{Fe}(\mathrm{CN})_{6}$, based on the Randles-Sevcik equation:

$$
I_{\mathrm{pa}}=2.69 \times 105 n^{3 / 2} A D_{\mathrm{R}}{ }^{1 / 2} v^{1 / 2} C_{0}
$$

where $I_{\text {pa }}$ refers to the anodic peak current, $n$ is the electron transfer number, $A$ is the surface area of the electrode, $D_{\mathrm{R}}$ is the diffusion coefficient, $C_{0}$ the concentration of $\mathrm{K}_{2} \mathrm{Fe}(\mathrm{CN})_{6}$, and $v$ is the scan rate. For $C_{0}=1.0 \mathrm{mmol} / \mathrm{L}$ in a $\mathrm{KCl}$ electrolyte $(0.10$ mol/L) with $n=1$ and $D_{\mathrm{R}}=7.6 \times 10^{-6} \mathrm{~cm} / \mathrm{s}$ and from the slope of the $I_{\mathrm{p}}-v^{1 / 2}$ relationship, the microscopic areas were calculated. The active surface areas were 0.055 and $0.10 \mathrm{~cm}^{2}$ for the CPE and the MWCNTPE, respectively. The results show that the

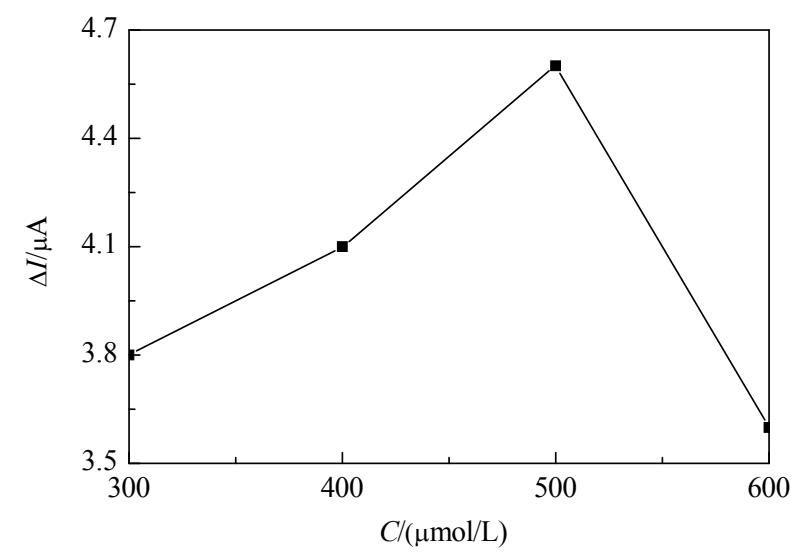

Fig. 1. Effect of 3,4-DHCA concentration on the net anodic peak current of L-cysteine $(700 \mu \mathrm{mol} / \mathrm{L})$. Scan rate $20 \mathrm{mV} / \mathrm{s}, \mathrm{pH}=7.0$. 


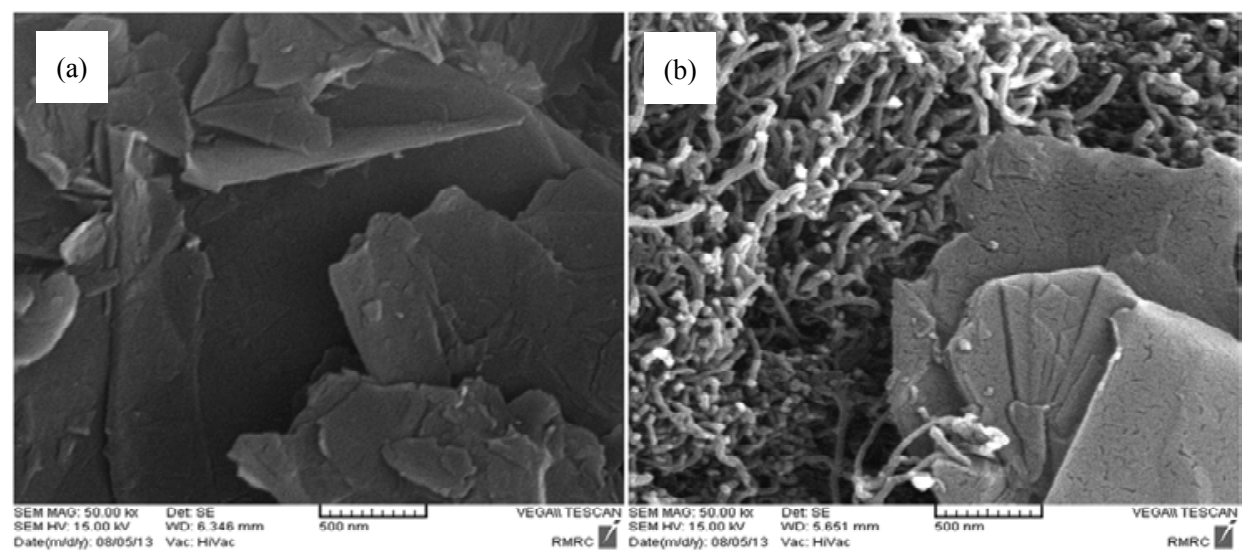

Fig. 2. SEM images of the CPE (a) and the MWCNTPE (b).

presence of the MWCNTPE increased the active surface of the electrode.

\subsection{Electrochemical behavior of 3,4-DHCA}

The electrochemical behavior of the mediator was characterized by cyclic voltammetry. Figure 3 (inset) shows cyclic voltammograms of 3,4-DHCA at the modified electrode in PBS $(\mathrm{pH}=7.0)$ at various scan rates in the range of $5-150 \mathrm{mV} / \mathrm{s}$ The experimental results indicate well-defined and reproducible anodic and cathodic peaks related to the 3,4-DHCA(red)/ 3,4-DHCA(ox) redox couple with quasi-reversible behavior and with a peak separation potential of $\Delta E_{\mathrm{p}}\left(E_{\mathrm{pa}}-E_{\mathrm{pc}}\right)=240 \mathrm{mV}$ These cyclic voltammograms were used to examine the variation in peak currents versus $v^{1 / 2}$. The plot of the anodic peak current was linearly dependent on $v^{1 / 2}$ with a correlation coefficient of 0.9938 at all scan rates (Fig. 3).

\subsection{Influence of $p H$}

To optimize the electrocatalytic response of the sensor to

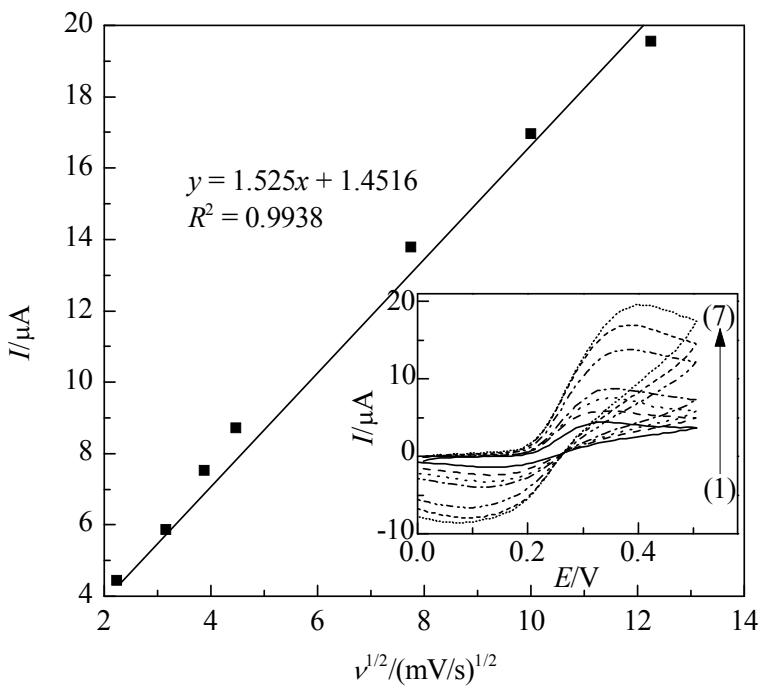

Fig. 3. Plot of $I_{\mathrm{pa}}$ versus $v^{1 / 2}$ for the oxidation of 3,4-DHCA $(500 \mu \mathrm{mol} / \mathrm{L})$ on the surface of the MWCNTPE. Inset: cyclic voltammograms at various scan rates in PBS (0.1 mol/L; pH = 7.0). (1) 5; (2) 10; (3) 15; (4) 20 ; (5) 60; (6) 100; (7) $150 \mathrm{mV} / \mathrm{s}$.
L-cysteine oxidation, we investigated the effect of solution $\mathrm{pH}$ on the electrocatalytic oxidation of L-cysteine PBS at different $\mathrm{pH}$ values $(5.0<\mathrm{pH}<8.0)$ using 3,4-DHCA as the mediator on the surface of the MWCNTPE. The influence of $\mathrm{pH}$ on both the peak current and peak potential was assessed by examining the electrode response in buffer solutions. The results show that the maximum electrocatalytic current was obtained at $\mathrm{pH}=7.0$. Therefore, $\mathrm{pH}=7.0$ was chosen for the determination of L-cysteine at the MWCNTPE in the presence of 3,4-DHCA.

\subsection{Catalytic activity during the electrooxidation of L-cysteine}

Figure 4(1) shows the voltammetric behavior of 3,4-DHCA in the buffer solution $(\mathrm{pH}=7.0)$. We obtained the cyclic voltammetric response for the electrochemical oxidation of L-cysteine $(700 \mu \mathrm{mol} / \mathrm{L})$ on the surface of the MWCNTPE (Fig. 4(3)), and on the surface of the CPE (Fig. 4(2)) in the presence of the mediator. Conversely, Fig. 4(4) and (5) were obtained in the absence of 3,4-DHCA. These results show that the sensor produces a large anodic peak current in the presence of L-cysteine without a cathodic counterpart (Fig. 4, curves (3)

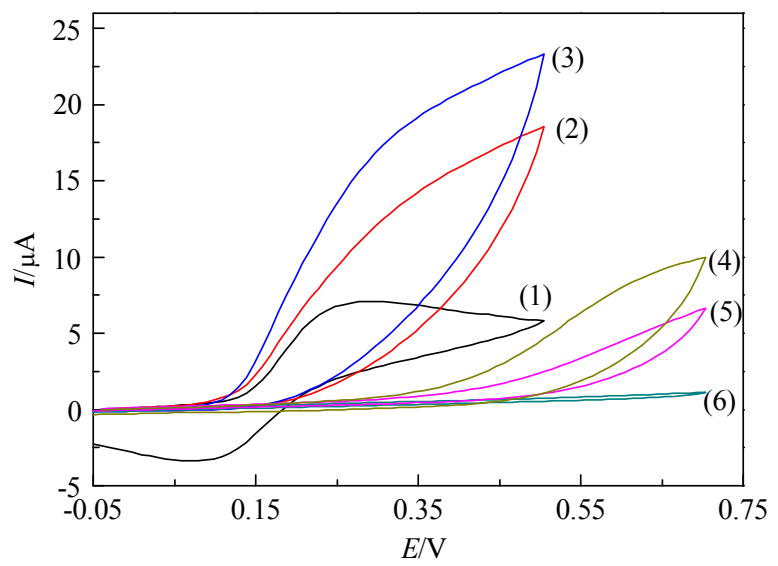

Fig. 4. Cyclic voltammograms of 3,4-DHCA $(500 \mu \mathrm{mol} / \mathrm{L})$ on the surface of the MWCNTPE in PBS $(0.1 \mathrm{~mol} / \mathrm{L} ; \mathrm{pH}=7.0)$ at a scan rate of $20 \mathrm{mV} / \mathrm{s}$ in the absence (1) and in the presence of L-cysteine $(500 \mu \mathrm{mol} / \mathrm{L})(3)$. (2) as (3) for the carbon paste electrode. (4) as (3) and (5) as (2) for the unmodified electrode (and in the absence of 3,4-DHCA). (6) Cyclic voltammogram of the MWCNTPE in PBS $(0.1 \mathrm{~mol} / \mathrm{L} ; \mathrm{pH}=7.0)$. 
and (2)). The current observed is associated with L-cysteine oxidation and not the oxidation of the modifier, which is shown by comparing the current without L-cysteine with that in the presence of L-cysteine. At the surface of the MWCNTPE and the CPE without a mediator, L-cysteine was oxidized at around 250 $\mathrm{mV}$. The electroactivity of L-cysteine on the MWCNTPE and the CPE in the presence of a mediator was significant (Fig. 4 curves (2) and (3)), with a strongly defined peak potential around 580 $\mathrm{mV}$ vs. the $\mathrm{Ag} / \mathrm{AgCl} / \mathrm{KCl}_{\text {sat }}$ electrode. Thus, a decrease in the overpotential and an enhancement of the peak current for L-cysteine oxidation were achieved with the MWCNTPE and the CPE in the presence of the mediator. Such behavior is indicative of an electrocatalytic (EC) mechanism (see Scheme 1) [31-34]. Similarly, when we compared the oxidation of L-cysteine on the surface of the MWCNTPE and the CPE with a mediator, a dramatic enhancement of the anodic peak current was apparent for the MWCNTPE versus that obtained for the CPE. In the presence of a mediator, the oxidation of L-cysteine can occur at the potential of the mediator, and the MWCNTs increased its oxidation current. These results clearly showed that the combination of the MWCNTPE and the mediator improved the characteristics of the electrode for the oxidation of L-cysteine.

The effect of scan rate on the electrocatalytic oxidation of L-cysteine $(700 \mu \mathrm{mol} / \mathrm{L})$ at the modified electrode was investigated by linear sweep voltammetry (Fig. 5 inset). The oxidation peak potential shifts with increasing scan rate toward a more positive potential, confirming the kinetic limitations of the electrochemical reaction.

A plot of peak height $\left(I_{\mathrm{p}}\right)$ against $v^{1 / 2}$ in the range $3-20 \mathrm{mV} / \mathrm{s}$ was compiled and found to be linear. This suggests that at sufficient overpotential the process is diffusion rather than surface controlled (Fig. 5). To obtain further information on the rate determining step, a Tafel plot was compiled for L-cysteine at the MWCNTPE in the presence of a mediator using the data derived from the rising part of the current-voltage curve (Fig. $6)$. The slope of the Tafel plot is equal to $n(1-\alpha) F / 2.3 R T$, which is $6.2337 \mathrm{~V}^{-1}$ decade. We calculated $n_{\alpha}$ to be 0.63 , and if it is assumed that $n=1$ then $\alpha=0.63$.

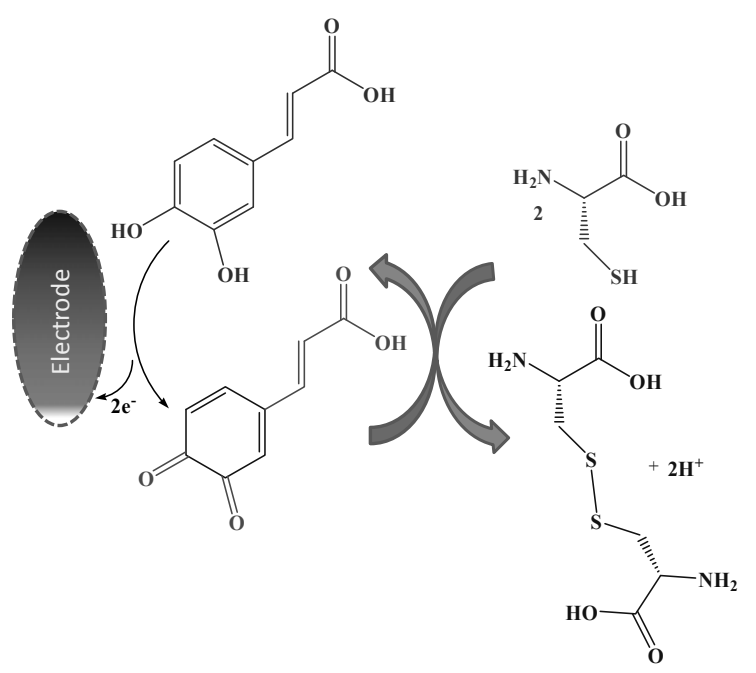

Scheme 1. Electrocatalytic mechanism for the determination of L-cysteine on the surface of the MWCNTPE and in the presence of the mediator.

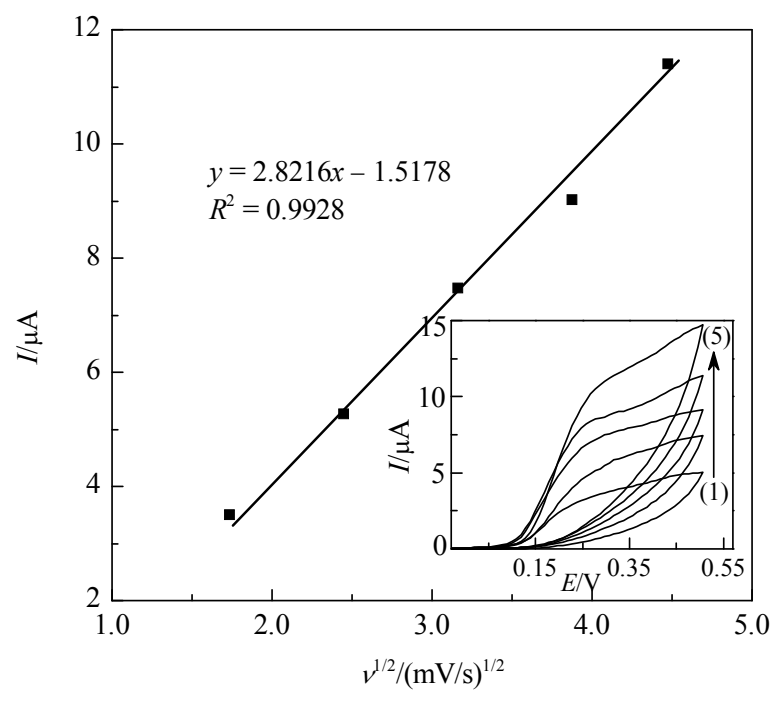

Fig. 5. Plot of $I_{\mathrm{pa}}$ versus $v^{1 / 2}$ for the oxidation of L-cysteine $(700 \mu \mathrm{mol} / \mathrm{L})$ in the presence 3,4-DHCA $(500 \mu \mathrm{mol} / \mathrm{L})$ on the surface of the MWCNTPE. Inset shows cyclic voltammograms of L-cysteine $(700$ $\mu \mathrm{mol} / \mathrm{L})$ in the presence 3,4 -DHCA $(500 \mu \mathrm{mol} / \mathrm{L})$ at various scan rates in PBS (0.1 mol/L; pH = 7.0). (1) 3; (2) 6; (3) 10; (4) 15; (5) $20 \mathrm{mV} / \mathrm{s}$.

In addition, the value of $\alpha n_{\alpha}$ ( $n_{\alpha}$ is the number of electrons involved in the rate-determining step) was calculated for the oxidation of L-cysteine at $\mathrm{pH}=7.0$ for both the MWCNTPE in the presence and in the absence of the mediator using the following equation:

$$
\alpha n_{\alpha}=0.048 /\left(E_{\mathrm{P}}-E_{\mathrm{P} / 2}\right)
$$

where $E_{\mathrm{P} / 2}$ is the potential corresponding to $I_{\mathrm{P} / 2}$. The values for $\alpha n_{\alpha}$ were found to be 0.63 and 0.25 for the MWCNTPE in the presence and in the absence of the mediator, respectively. The results show that the over-potential of L-cysteine oxidation is reduced at the MWCNTPE in the presence of 3,4-DHCA, and that the rate of the electron transfer process is greatly enhanced. This phenomenon was confirmed by the larger $I_{\text {pa }}$ values obtained during the cyclic voltammetry of the MWCNTPE.

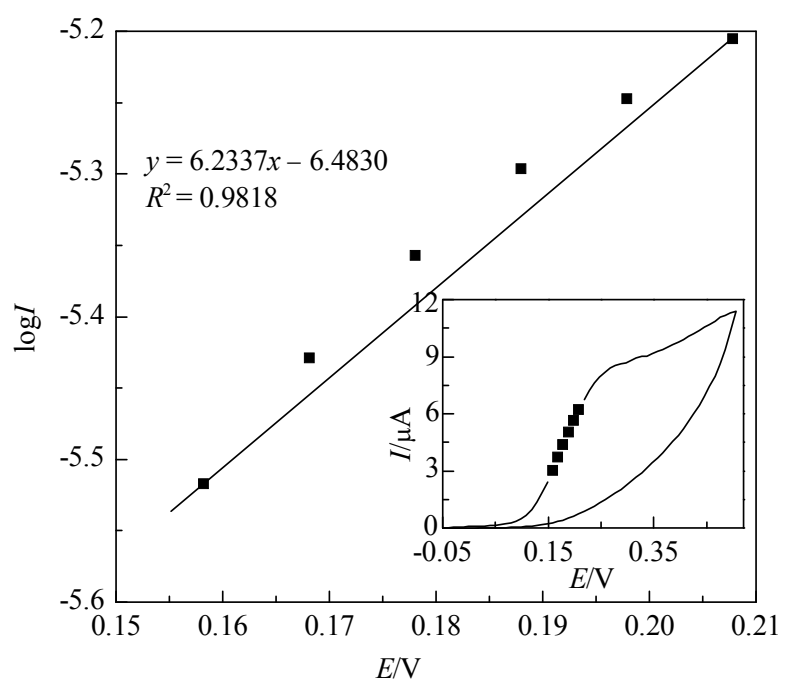

Fig. 6. Tafel plot of 3,4-DHCA $(500 \mu \mathrm{mol} / \mathrm{L})$ on the surface of the MWCNTPE in PBS ( $0.1 \mathrm{~mol} / \mathrm{L} ; \mathrm{pH}=7.0)$ at a scan rate of $15 \mathrm{mV} / \mathrm{s}$ in the presence of L-cysteine $(700 \mu \mathrm{mol} / \mathrm{L})$. 
Chronoamperometric measurements of L-cysteine at the MWCNTPE in the presence of the mediator were carried out by setting the working electrode potential to $0.0 \mathrm{~V}$ (at the first potential step) and to $0.4 \mathrm{~V}$ (at the second potential step) vs. $\mathrm{Ag} / \mathrm{AgCl} / \mathrm{KCl}_{\text {sat }}$ for 200 and $300 \mu \mathrm{mol} / \mathrm{L}$ of L-cysteine in buffered aqueous solutions ( $\mathrm{pH}=7.0$ ) (Fig. 7(a)). The rate constant $\left(k_{\mathrm{h}}\right)$ of the chemical reaction between 3,4-DHCA and L-cysteinewas determined according to the method of Galus [35]:

$$
I_{\mathrm{C}} / I_{\mathrm{L}}=\pi^{1 / 2} \gamma^{1 / 2}=\pi^{1 / 2}\left(k_{\mathrm{h}} t\right)^{1 / 2}
$$

where $I_{C}$ is the catalytic current of 3,4-DHCA in the presence of L-cysteine and $I_{\mathrm{L}}$ is the limiting current in the absence of L-cysteine. From the slope of $I_{\mathrm{C}} / I_{\mathrm{L}}$ versus $t^{1 / 2}$ for two different concentrations of L-cysteine, the average value of $k_{\mathrm{h}}$ was calculated to be $2.37 \times 10^{2} \mathrm{~mol}^{-1} \mathrm{~L} \mathrm{~s}^{-1}$ (Fig. 7(b)). This rate constant explains the sharp catalytic peak observed for the oxidation of
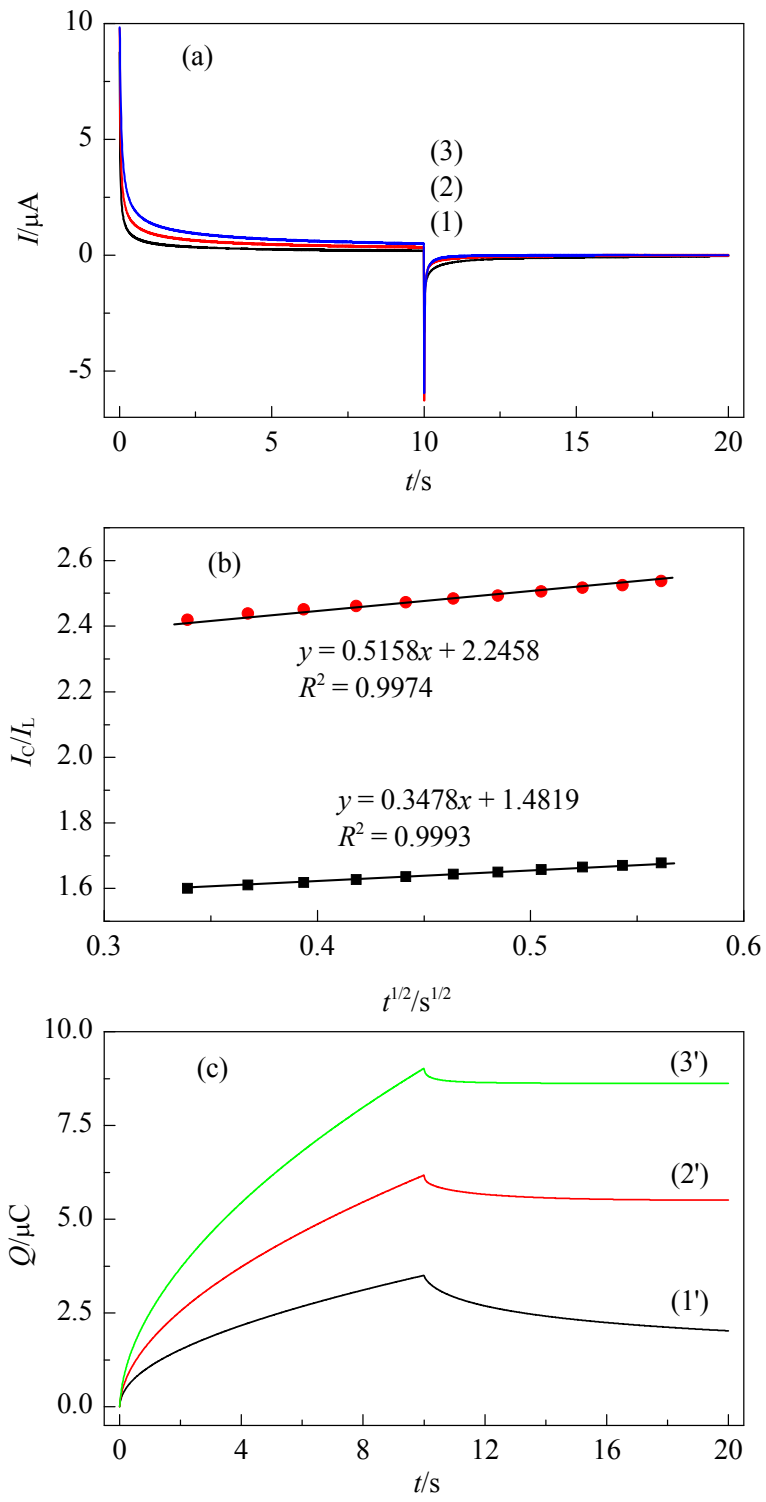

Fig. 7. (a) Chronoamperograms obtained at the MWCNTPE in the absence (1) and in the presence of 200 (2) and $300 \mu \mathrm{mol} / \mathrm{L}$ of L-cysteine (3) in a buffer solution ( $\mathrm{pH}=7.0$ ). (b) Dependence of $I_{\mathrm{C}} / I_{\mathrm{L}}$ on the $t^{1 / 2}$, as derived from the chronoamperogram data. (c) Charge-time curves (1') for curve (1), (2') for curve (2), and (3') for curve (3).
L-cysteine on the surface of the MWCNTPE in the presence of the mediator.

Figure 7(c) shows double-potential step chronocolougrams for the mediator in the absence and presence of different concentrations of L-cysteine on the surface of the MWCNTPE. The results show that forward and backward potential step chronocoloumetry in a blank buffer solution yields very symmetrical chronocolougrams. These reveal almost equal charge consumption for both oxidation and reduction in the redox system of the mediator on the surface of the MWCNTPE. However, in the presence of L-cysteine, the charge value associated with forward chronocoulometry was significantly higher than that observed for backward chronocoulometry. This behavior is typically expected for electrocatalysis at chemically modified electrodes [36-44].

\subsection{Calibration plot and detection limit}

Linear sweep voltammetry (LSV) was used for the determination of L-cysteine. The LS voltammograms clearly showed a linear dynamic range wherein the plot of the peak current versus L-cysteine concentration was linear for $0.4-115 \mu \mathrm{mol} / \mathrm{L}$ with a regression equation of $I_{\mathrm{p}}(\mu \mathrm{A})=(0.024 \pm 0.003) C+$ $(3.0909 \pm 0.7021)\left(R^{2}=0.9958, n=9\right)$, where $C$ is the concentration of L-cysteine $(\mu \mathrm{mol} / \mathrm{L})$ and $I_{\mathrm{p}}$ is the peak current. The detection limit was determined to be $0.25 \mu \mathrm{mol} / \mathrm{L}$ of L-cysteine according to the definition: $Y_{\mathrm{LOD}}=Y_{\mathrm{B}}+3 \sigma$.

\subsection{Interference studies}

Interference studies were carried out using several chemical substances before the application of the proposed method for the assay of L-cysteine in urine and serum. The influence of various substances as potential interference compounds during the determination of L-cysteine $(5.0 \mu \mathrm{mol} / \mathrm{L})$ under optimum conditions was studied. The tolerance limit was defined as the maximum concentration of an interfering substance that caused an error less than 5\% for the determination of L-cysteine. The results are given in Table 1, which shows that the peak current of L-cysteine is not affected by any conventional cations, anions, or organic substances.

\subsection{Stability and reproducibility}

The repeatability and stability of the MWCNTPE in the presence of the mediator were investigated by LSV measure-

Table 1

Interference study for the determination of L-cysteine $(5.0 \mu \mathrm{mol} / \mathrm{L})$ under optimized conditions.

\begin{tabular}{lc}
\hline Species & Tolerance limit $(\mathrm{m} / \mathrm{m})$ \\
\hline Glucose, Fructose, Lactose, Sucrose, Hystidine, & 1000 \\
Alanine, Phenyl alanine, Methionine, Glycine, & \\
$\mathrm{SCN}^{-}, \mathrm{SO}_{4}{ }^{2-}, \mathrm{Br}^{-}, \mathrm{L}-\mathrm{T}$-Threonine, L-isoleucine, Urea, & \\
Ethanol, Methanol, Folic acid & 800 \\
Starch & saturation \\
Ascorbic acid & 2 \\
\hline${ }^{*}$ Interference of ascorbic acid can be minimized by adding ascorbic \\
oxidize (1 mmol/L) to the solution.
\end{tabular}


Table 2

Determination of L-cysteine in real samples $(n=3)$.

\begin{tabular}{lcccc}
\hline Sample & Cysteine added $(\mu \mathrm{mol} / \mathrm{L})$ & Cysteine found $(\mu \mathrm{mol} / \mathrm{L})$ & Recovery $(\%)$ & Cysteine found with published method $(\mu \mathrm{mol} / \mathrm{L})$ \\
\hline Water & - & $<$ limit detection & - & $<$ limit detection \\
& $5 / 0$ & $5 / 35 \pm 0 / 38$ & 107 & $4 / 85 \pm 0 / 75$ \\
Serum & $20 / 0$ & $21 / 01 \pm 1 / 11$ & 105 & - \\
& - & $<$ limit detection & - & $<$ limit detection \\
& $10 / 0$ & $10 / 44 \pm 0 / 54$ & 104 & $10 / 82 \pm 0 / 95$ \\
Urine & $30 / 0$ & $29 / 85 \pm 0 / 68$ & - & - \\
& - & $<$ limit detection & 104 & $15 / 65 \pm 0 / 75$ \\
\hline
\end{tabular}

\pm standard deviation for $n=3$.

ments of L-cysteine $(5.0 \mu \mathrm{mol} / \mathrm{L})$. The relative standard deviation (RSD\%) for five successive assays was $1.5 \%$. When using five different electrodes, the RSD\% for the five measurements was $2.5 \%$. When the electrode was stored in the laboratory, the modified electrode retained $96 \%$ of its initial response after a week and 93\% after $35 \mathrm{~d}$. These results indicate that the MWCNTPE has good stability and reproducibility, and can be used for L-cysteine analysis.

\subsection{Determination of L-cysteine in real samples}

To evaluate the applicability of the proposed method to the determination of $\mathrm{HCy}$ in real samples, we analyzed for L-cysteine in water, serum, and urine. The standard addition method was used to measure L-cysteine concentrations in real samples. The proposed method was also compared with a published method [2], and the results are given in Table 2. It indicates that the determination of L-cysteine using the electrode is effective and can be applied to the detection of L-cysteine in real samples.

\section{Conclusions}

The electrochemical behavior of 3,4-DHCA and MWCNTPE as a new electrochemical sensor for L-cysteine determination was studied by cyclic voltammetry and chronoamperometry. It was found that with cyclic voltammetry, the oxidation of L-cysteine occurred at a potential of about $320 \mathrm{mV}$ less positive than that of an unmodified carbon nanotubes paste electrode. The catalytic peak current obtained by LSV was linearly dependent on the L-cysteine concentration with a minimum of $0.25 \mu \mathrm{mol} / \mathrm{L}$. The current sensitivity, low detection limit, and high selectivity of the MWCNTPE in the presence of 3,4-DHCA for the detection of L-cysteine prove its potential in sensing application for the determination of L-cysteine in real samples.

\section{Acknowledgments}

The authors wish to thank Graduat University of Advanced Technology, Kerman and Majlesi Branch, Islamic Azad University, for their support.

\section{References}

[1] The Primary Structure Of Proteins Is the Amino Acid Sequence. The Microbial World. University of Wisconsin-Madison Bacteriology Department. Retrieved 16 September 2012.

[2] Kazemi S, Karimi-Maleh H, Hosseinzadeh R, Faraji F. Ionics, 2013, 19: 933

[3] Chwatko G, Bald E. Talanta, 2000, 52: 509

[4] Friedman M, Krull L H, Cavins J F. J Biolog Chem, 1970, 245: 3868

[5] Saetre R, Rabenstein D L. Anal Biochem, 1978, 90: 684

[6] Jin W R, Wang Y.J Chromatog A, 1997, 769: 307

\section{Graphical Abstract}

Chin. J. Catal., 2014, 35: 1166-1172 doi: 10.1016/S1872-2067(14)60065-6

\section{Application of 3,4-dihydroxycinnamic acid as a suitable mediator and multiwall carbon nanotubes as a sensor for the electrocatalytic determination of L-cysteine}

Mohsen Keyvanfard*, Rasoul Salmani-mobarakeh, Hassan Karimi-Maleh*, Khadijeh Alizad

Islamic Azad University, Iran;

Graduate University of Advanced Technology, Iran

A modified multiwall carbon nanotubes paste electrode was used as a voltammetric sensor for the determination of L-cysteine in the presence of 3,4-dihydroxycinnamic acid as a mediator.

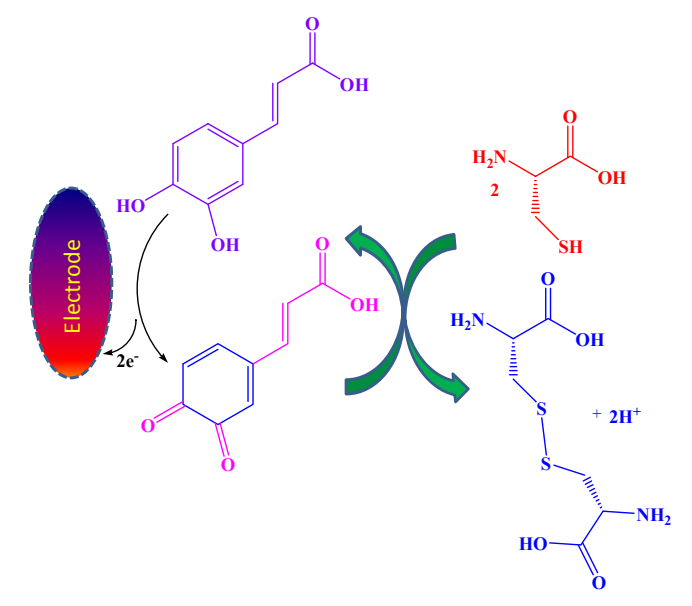


[7] Chrastil J. Analyst, 1990, 115: 1383

[8] Gaitonde M K. Biochem J, 1967, 104: 627

[9] Wu F Y, Liao W S, Wu Y M, Wan X F. Spect Lett, 2008, 41: 393

[10] Giljanović J, Brkljača M, Prkić A. Molecules, 2011, 16: 7224

[11] Nie L H, Ma H M, Sun M, Li X H, Su M H, Liang S C. Talanta, 2003, 59: 959

[12] Ensafi A A, Dadkhah-Tehrani S, Karimi-Maleh H. Anal Sci, 2011, 27: 409

[13] Amini M K, Khorasani J H, Khaloo S S, Tangestaninejad S. Anal Biochem, 2003, 320: 32

[14] Perevezentseva D 0, Gorchakov E V. J Solid State Electrochem, 2012, 16: 2405

[15] Ahmad M, Pan C F, Zhu J.J Mater Chem, 2010, 20: 7169

[16] Ensafi A A, Karimi-Maleh H.J Electroanal Chem, 2010, 640: 75

[17] Ensafi A A, Bahrami H, Karimi-Maleh H, Mallakpour S. Chin J Catal (催化学报), 2012, 33: 1919

[18] Ensafi A A, Lotfi M, Karimi-Maleh H. Chin J Catal (催化学报), 2012, 33: 487

[19] Tavana T, Khalilzadeh M A, Karimi-Maleh H, Ensafi A A, Beitollahi H, Zareyee D. J Mol Liq, 2012, 168: 69

[20] Karimi-Maleh H, Biparva P, Hatami M. Biosens Bioelect, 2013, 48: 270

[21] Elyasi M, Khalilzadeh M A, Karimi-Maleh H. Food Chem, 2013, 141: 4311

[22] Beitollah H, Goodarzian M, Khalilzadeh M A, Karimi-Maleh H, Hassanzadeh M, Tajbakhsh M. J Mol Liq, 2012, 173: 137

[23] Keyvanfard M, Khosravi V, Karimi-Maleh H, Alizad K, Rezaei B. J Mol Liq, 2013, 177: 182

[24] Keyvanfard M, Shakeri R, Karimi-Maleh H, Alizad K. Mater Sci Eng C, 2013, 33: 811

[25] Ensafi A A, Karimi-Maleh H, Keyvanfard M. Int J Environ Anal Chem, 2013, 93: 650

[26] Moradi R, Sebt S A, Karimi-Maleh H, Sadeghi R, Karimi F, Bahari A, Arabi H. Phys Chem Chem Phys, 2013, 15: 5888
[27] Keyvanfard M, Ensafi A A, Karimi-Maleh H. J Solid State Electrochem, 2012, 16: 2949

[28] Karimi-Maleh H, Keyvanfard M, Alizad K, Khosravi V, Asnaashariisfahani M. Int J Electrochem Sci, 2012, 7: 6816

[29] Mokhtari A, Karimi-Maleh H, Ensafi A A, Beitollahi H. Sens Actuators $B, 2012,169: 96$

[30] Roodbari Shahmiri M, Bahari A, Karimi-Maleh H, Hosseinzadeh R, Mirnia N. Sens Actuators B, 2013, 177: 70

[31] Karimi-Maleh H, Ensafi A A, Allafchian A R. J Solid State Electrochem, 2010, 14: 9

[32] Ma X Y, Chao M Y. Anal Methods, 2013, 5: 5823

[33] Mirmomtaz E, Ensafi A A, Karimi-Maleh H. Electroanalysis, 2008, 20: 1973

[34] Rafiee B, Fakhari A R. Biosens Bioelect, 2013, 46: 130

[35] Galus Z. Fundumentals of Electrochemical Analysis. New York: Ellis Horwood, 1976

[36] Raoof J B, Ojani R, Karimi-Maleh H. Electroanalysis, 2008, 20: 1259

[37] Ensafi A A, Karimi-Maleh H, Mallakpour S, Hatami M. Sens Actuators $B, 2011,155: 464$

[38] Ensafi A A, Karimi-Maleh H, Mallakpour S, Rezaei B. Colloids Surf B, 2011, 87: 480

[39] Keyvanfard M, Karimi-Maleh H, Alizad K. Chin J Catal (催化学报), 2013, 34: 1883

[40] Afzali D, Karimi-Maleh H, Khalilzadeh M A. Environ Chem Lett, 2011, 9: 375

[41] Ensafi A A, Karimi-Maleh H, Ghiaci M, Arshadi M. J Mater Chem, 2011, 21: 15022

[42] Ensafi A A, Dadkhah-Tehrani S, Karimi-Maleh H. Anal Sci, 2011, 27: 409

[43] Ensafi A A, Karimi-Maleh H, Mallakpour S. Electroanalysis, 2011, 23: 1478

[44] Taheri A R, Mohadesi A, Afzali D, Karimi-Maleh H, Moghaddam H M, Zamani H, Zad Z R. Int J Electrochem Sci, 2011, 6: 171 